\title{
TRUST IN POLISH-RUSSIAN RELATIONS. IS IT POSSIBLE?
}

\begin{abstract}
To trust or not to trust? Virtually all the actors of international relations, both state and non-state ones have to face this Hamletian dilemma. Understandably, trust constitutes the foundation of all social interactions and systems, including those extending the borders of nation-state. The question of trust in the PolishRussian relations is crucial enough to be asked not only by scientists but also by societies and decision makers. The aim of the article is to identify the causes of mistrust in relations between neighbors - Poland and Russia.
\end{abstract}

\section{Key words}

trust, distrust, mistrust, Poland, Russia, Polish-Russian relations, mutual perception

\section{Introduction}

Trust is a luxury. In relations between states, almost no one can afford this comfort. The main reason of that is the principle of limited trust, which is a feature of anarchic international relations. Not only is this rule ingrained in the realist paradigm, but also it is a frequent way of thinking about "the others" by human beings. While people have a natural predisposition to trust the closest family members (parents or siblings), states do not have relatives, who would be the first objects of trust. Children's trust towards their parents is unconditional. Although, according to Hardin (2009, p. 26), "trust does not apply to a person, we trust, but to the situation in which his or her interests include ours", generally speaking, it is natural for the interest of parents to include those of their child.

* Agata Włodkowska-Bagan, Associate Professor, Institute of International Relations, National Security Faculty, National Defence University in Warsaw. e-mail: a.wlodkowska. bagan@gmail.com. 